\title{
Insight into octoploid strawberry (Fragaria) subgenome composition revealed by GISH analysis of pentaploid hybrids
}

\begin{tabular}{|r|l|}
\hline Journal: & Genome \\
\hline Manuscript ID & gen-2015-0116.R1 \\
\hline Manuscript Type: & Article \\
\hline Date Submitted by the Author: & 09-Nov-2015 \\
\hline Complete List of Authors: & $\begin{array}{l}\text { Liu, Bo; Texas A\&M University, Soil and Crop Sciences } \\
\text { Poulsen, Elizabeth; Kansas State University, Veterinary Diagnostic } \\
\text { Laboratory } \\
\text { Davis, Thomas; University of New Hampshire, Biological Sciences }\end{array}$ \\
\hline Keyword: & $\begin{array}{l}\text { genome composition, interspecific hybrid, genomic in situ hybridization, } \\
\text { rDNA-FISH, <i>Fragaria </i> }\end{array}$ \\
\hline &
\end{tabular}

\section{SCHOLARONE ${ }^{\text {'m }}$ \\ Manuscripts}




\section{Title:}

Insight into octoploid strawberry (Fragaria) subgenome composition revealed by GISH analysis of pentaploid hybrids

\section{Authors:}

Bo Liu, Elizabeth G. Poulsen, Thomas M. Davis

Department of Biological Sciences, University of New Hampshire, Durham, NH 03824

BL: present address: Department of Soil and Crop Sciences, Texas A\&M AgriLife Research, Texas A\&M University, College Station, TX 77843; bo.liu@ag.tamu.edu

EGP: Veterinary Diagnostic Laboratory, Kansas State University, Manhattan, KS 66506; epoulsen@vet.k-state.edu

TMD, corresponding author: Department of Biological Sciences, University of New Hampshire, Durham, NH 03824; tom.davis@unh.edu 


\section{Abstract}

As the product of interspecific hybridization between its two ancestral octoploid $(2 n=8 x$ $=56)$ species $(F$. chiloensis and $F$. virginiana), the cultivated strawberry $F$. ×ananassa is among the most genomically complex of crop plants, harboring subgenomic components derived from as many as four different diploid ancestors. To physically visualize the octoploids' subgenome composition(s), we launched molecular cytogenetic studies using genomic in situ hybridization (GISH), comparative GISH (cGISH), and rDNA-FISH techniques. First, GISH resolution in Fragaria was tested by using diploid and triploid hybrids with predetermined genome compositions. Then, observation of an octoploid genome was implemented by hybridizing chromosomes of pentaploid $(2 n=5 x=35)$ hybrids from $F$. vesca $\mathrm{x} F$. virginiana with genomic DNA probes derived from diploids $(2 n=2 x=14) F$. vesca and F. iinumae, which have been proposed by phylogenetic studies to be closely related to the octoploids yet highly divergent from each other. GISH and cGISH results indicated that octoploid-derived gametes $(n=4 x=28)$ carried seven chromosomes with hybridization affinities to $F$. vesca, while the remaining 21 chromosomes displayed varying affinities to $F$. iinumae, indicating differing degrees of subgenomic contribution to the octoploids by these two putatively ancestral diploids. Combined rDNA-FISH revealed severe $25 \mathrm{~S}$ rDNA loss in both the $F$. vesca- and $F$. iinumae-like chromosome groups, while only the prior group retained its $5 \mathrm{~S}$ loci.

\section{Key words}


Fragaria, genome composition, interspecific hybrid, genomic in situ hybridization, rDNAFISH

\section{Introduction}

The cultivated strawberry Fragaria $\times$ ananassa is a highly-valued fruit crop species with a steadily increasing consumer demand (Folta and Davis 2006), and the fruits are appreciated for their unique flavor and nutritious qualities. Having arisen from an interspecific hybridization between two ancestral octoploid $(2 n=8 x=56)$ species $F$. chiloensis and $F$. virginiana about 250 to 300 years ago (Darrow 1966), F. ×ananassa is among the most genomically complex of crop plants (Marx 2013), harboring eight sets of chromosomes derived from as many as four different diploid ancestors (Davis et al. 2009). Establishing the identities of the diploid genome donors to the Fragaria octoploids has been of long-standing interest. Octoploid strawberry subgenomic ancestry and composition were initially studied by interspecific hybridizations and cytogenetic methods, from which various genomic composition models were proposed. These models have implied two or three distinctly different genome types (A type, B type, and C type), with further differentiation (e.g. A vs. A') within one or more types (Fedorova 1946; Senanayake and Bringhurst 1967; Bringhurst 1990). Recent molecular phylogenetic studies utilizing DNA sequences of various nuclear gene loci and chloroplast genomes suggest a close relationship between the two ancestral octoploid species, the sequences of which cluster cladistically with those of diploids $F$. vesca and F. mandshurica, or F. iinumae (Harrison et al. 1997; Potter et al. 2000; Rousseau-Gueutin et al. 2009; Njuguna et al. 2013; DiMeglio et al. 2014). A recent genome-scale sequence 
analysis and phylogenetic study not only confirmed the ancestral roles of $F$. vesca and $F$. iinumae, but also reported that one subgenome in the octoploids was $F$. vesca-like while the other three were F. iinumae-like (Tennessen et al. 2014). Even more recently, Sargent et al. (2015) employed a linkage analysis of subgenome-specific "haploSNP" markers in octoploid F. $\times$ ananassa to assign chromosome pairs to subgenomic categories, on which basis seven chromosome pairs could be definitely assigned to an $F$. vesca-like subgenome, seven pairs could be provisionally assigned to an F. iinumae-like subgenome, and 14 pairs could not be differentiated into two discrete sets or assigned to diploid ancestral sources .

Genomic in situ hybridization (GISH), a variant of the fluorescence in situ hybridization (FISH) technique, applies whole genomic probes in suppressive hybridizations to visualize individual genomes in interspecific hybrids (e.g. Arabidopsis, Ali et al. 2004) and allopolyploids (e.g. Musa, Osuji et al. 1997). In Fragaria, the only GISH applications have been to a hybrid between diploid F. nilgerrensis and the cultivated strawberry (Ma et al. 2005), and to $F$. ×ananassa 'Hokowase' (Nathewet and Yanagi 2014). Our study was aimed at exploring the putative progenitor roles of F. vesca and F. iinumae in origins of the octoploids by cytological visualization of differentiated chromosome groups. In addition, building upon our previous work, which revealed a substantial loss of ribosomal DNA loci in the octoploid Fragaria species (Liu and Davis 2011), we combined FISH and GISH examinations to further explore the fates of rDNA loci within subgenomic components of the octoploid genome.

The extremely small chromosome sizes and the high chromosome number in octoploid strawberries make molecular cytogenetic studies quite difficult. We utilized two strategies to 
facilitate our investigations. As an initial test of concept, we used a diploid interspecific hybrid and an allotriploid $(2 n=3 x=21)$ species to test the feasibility and resolution of GISH and cGISH in Fragaria. Then, as a novel means of exploring octoploid subgenome composition, we constructed and studied pentaploid $(2 n=5 x=35)$ hybrids, the genomes of which were composed of one $F$. vesca genome copy $(n=x=7)$ plus a gametic chromosome complement $(n=4 x=28)$ from a representative of the octoploid species $F$. virginiana (Davis et al. 2009; Poulsen 2010). By virtue of their advantageously reduced number of chromosome sets, such pentaploid hybrids were intended to serve as convenient surrogates for the octoploid parent itself.

\section{Materials and methods}

Diploid species and accessions $F$. vesca 'Yellow wonder', $F$. vesca 'Hawaii4', $F$. nilgerrensis (CFRA 1358), F. viridis (CFRA 341), and F. iinumae (CFRA 1850) were used for construction of GISH probes, and F. vesca 'Hawaii4' was used for blocking. Accessions with CFRA prefixes were obtained from the National Clonal Germplasm Repository (NCGR), Corvallis, Oregon. Total genomic DNA was isolated from unexpanded leaf tissue using a modified CTAB protocol (Orcheski and Davis, 2010). Probes were labeled with either DIG11-dUTP or Biotin-11-dUTP by nick-translation reactions according to the label manufacturer's instructions (Roche Diagnostics, Indianapolis, Indiana). For blocking, unlabeled genomic DNA was sheared down by autoclave and the final fragment size was between 100 to $300 \mathrm{bp}$. Cot-1 DNA of $F$. vesca 'Hawaii4' was prepared according to Zwick et al. (1997). 
Our GISH and cGISH investigations employed three types of hybrids: diploid interspecific hybrid 'YWx1358', which was developed by our lab from a cross between $F$. vesca 'Yellow Wonder' (as female) and F. nilgerrensis (CFRA 1358); triploid accession GS104 of the hybrid species $F$. $\times$ bifera obtained from Guenter Staudt and thought to have arisen from the union of a reduced female gamete from $F$. vesca and an unreduced male gamete from $F$. viridis (Staudt et al. 2003); and two pentaploid hybrid individuals (5xH and 5xAJ) developed by our lab from a cross between $F$. vesca 'Hawaii4' as female and an octoploid intraspecific hybrid LB48, the parents of which were F. virginiana subsp. virginiana CFRA 1994 (local number L1) as female and F. virginiana subsp. glauca CFRA 1992 (local number BC6) as male (Davis et al. 2009; Poulsen 2010).

The chromosome preparation followed Liu and Davis (2011). GISH and cGISH employed the rDNA-FISH protocol described in that same work, except that the hybridization time was two days. In cGISH on the diploid hybrid YWx1358 and the pentaploid hybrid 5xH, the ratio between differentially labeled probes in each case was $1: 1$ and no blocking DNA was applied. In GISH on $F$. $\times$ bifera, Cot-1 DNA of $F$. vesca 'Hawaii4' was used as a block to the $F$. viridis DNA probe in a block:probe ratio of 20:1. In GISH on the pentaploid 5xAJ, total genomic DNA of $F$. vesca 'Hawaii4' was used as a block to the $F$. iinumae DNA probe in a block:probe ratio of 30:1. Following the GISH experiment on 5xAJ, the same chromosome preparation was hybridized with 25S and 5S rDNA probes according to Liu and Davis (2011).

\section{Results}

Our GISH exploration in strawberries started with diploid interspecific hybrid 
'YWx1358'. When genomic DNAs of its two parents, $F$. vesca 'Yellow Wonder' and $F$. nilgerrensis (CFRA 1358), were differentially labeled and hybridized simultaneously to the hybrid's chromosomes in a cGISH procedure, seven chromosomes were highlighted in red by the $F$. vesca probe and the other seven in green by the F. nilgerrensis probe (Figure 1), in agreement with the expected subgenomic composition of this hybrid. The clear differentiation of the two contributing subgenomes in this diploid hybrid thus demonstrated the feasibility of cGISH analysis in strawberry accessions containing sufficiently divergent genomes.

To test the resolution of GISH between genomes with a closer relationship, we employed a triploid accession of $F$. $\times$ bifera and performed GISH with $F$. viridis DNA as a probe and unlabeled F. vesca 'Hawaii4' Cot-1 DNA as a block. All chromosomes displayed signals with varying intensities, but none had complete and uniformly intense signal coverage (Figure 2a). However, of the 21 chromosomes, 15 chromosomes could be distinguished on the basis of their stronger green signals, while the remaining six exhibited lower intensities and sparser distributions of signals (orange arrows in Figure 2a). In addition, among the former 15 chromosomes, six had particularly intense highlighting of distal zones (white arrows in Figure 2a). After GISH, we hybridized $25 \mathrm{~S}$ and $5 \mathrm{~S}$ rDNA FISH probes to the same chromosome preparation and identified nine $25 \mathrm{~S}$ and three 5S rDNA sites (Figure 2b) as reported previously for F. × bifera accession GS104 (Liu and Davis, 2011). The six distally located zones that had displayed strong GISH signals were all found to be sites of $25 \mathrm{~S}$ rDNA signals (white arrows in Figure 2b), suggesting that the 25S rDNA sequences in the $F$. viridis genome were still preferentially hybridized with $F$. viridis DNA in spite of the presence of much more 
F. vesca Cot-1 blocking DNA, which contains only highly repetitive DNA including rDNA sequences. Meanwhile, the three 25S rDNA loci in the $F$. vesca genome (Figure $2 b$ ) did not produce GISH highlighting zones, indicating that they had all been blocked by the homologous blocking DNA. Fifteen chromosomes showed significant GISH signals instead of the expected 14. A possible explaination for this discrepency is that the extra one may have been derived from $F$. vesca, as indicated by its $25 \mathrm{~S}$ rDNA site (arrowhead in Figure 2b), which was blocked in GISH but showed up in the sequential FISH.

After the feasibilities of GISH and cGISH were evaluated in diploid and triploid hybrids with predetermined genome constitutions and found to be informative in the presence of higher genomic divergence, a similar approach was taken with our pentaploid hybrids. First, cGISH with a 1:1 ratio of probes of differentially labeled $F$. vesca 'Yellow Wonder' DNA and F. iinumae DNA was performed in pentaploid individual $5 \mathrm{xH}$. As shown in figure 3,14 chromosomes were highlighted by the $F$. vesca probe in red color, while 21 showed green color in various degrees of brightness by the F. iinumae probe. Among the 14 chromosomes with predominantly red signals, seven are presumed to be those contributed to the pentaploid by its diploid, female parent, F. vesca 'Hawaii4'. On this basis the other seven red-colored chromosomes must have come from octoploid paternal parent, F. virginiana LB48, by way of its gamete, and thus may constitute an $F$. vesca-like subgenomic set. Notably, the two putative sets of red-colored chromosomes differ in signal intensity, and we reasonably infer that the set with the brighter signals is that from $F$. vesca itself, given that the latter is the source of the respective probe, while the set with the lesser signal intensity is the $F$. vesca-like set 
contributed by $F$. virginiana. In making these groupings, we also took into account differences in single-color signal intensities (red versus green - not shown), whereas the displayed images integrate both probe color signals. However, we acknowledge that a definitive grouping of chromosomes into coherent sets of seven will require additional forms of discrimination, such as might be provided by chromosome-specific FISH signals.

Similarly, 21 chromosomes had predominantly green signals, indicating their greater affinities to the F. iinumae probe than to the $F$. vesca probe, and therefore suggesting their closer ancestral relationships to $F$. iinumae rather than to $F$. vesca. Various signal intensities among these chromosomes may be indicative of their differing phylogenetic distances from $F$. iinumae. The 21 chromosomes were further grouped into three sets based on the relative brightness of their signals (Figure $3 \mathrm{~b}$ and $3 \mathrm{c}$ ). The sets with the brightest green signals display the greatest affinity with $F$. iinumae, while the set with the weakest signals displays the least.

In our previous work on identifying rDNA loci in strawberry genomes, we observed disproportionately low numbers of both $25 \mathrm{~S}$ and $5 \mathrm{~S}$ rDNA loci in octoploids compared to those in species at low ploidy levels (from diploids to tetraploids; Liu and Davis 2011). To identify possible patterns of subgenome-specific loss of rDNA loci in octoploid strawberries, we performed a GISH in a pentaploid individual 5xAJ followed by an rDNA-FISH analysis. In GISH, F. iinumae DNA was used as a probe (green signals) and unlabeled $F$. vesca 'Hawaii4' DNA as a block. Distinct green signals were seen on 21 chromosomes. This result was consistent with the prior cGISH examination in suggesting that up to three octoploid subgenomes have some affinity to $F$. iinumae. The other 14 chromosomes had just a few very 
localized green signals on the predominantly orange (DAPI-stained) background (Figure 4a), and are presumed to correspond to the $F$. vesca and $F$. vesca-like genome sets identified in cGISH. In contrast to $F$. $\times$ bifera, in which $25 \mathrm{~S}$ rDNA loci in one genome were particularly highlighted by its parent's labeled whole-genomic DNA (Figure 2a), we did not observe any particularly highlighted chromosomal zones generated by prominent GISH signals in 5xAJ.

In a sequential FISH analysis of pentaploid 5xAJ, nine 25S and two 5S rDNA loci were observed (Figure 4b). Meanwhile, we also detected rDNA loci in LB48, which is the immediate parent of our pentaploid hybrids, and observed a consistent $25 \mathrm{~S}$ rDNA locus number of ten (data not shown). This locus number was the same as in the two $F$. virginiana parents of LB48 (Liu and Davis 2011). F. vesca 'Hawaii4' has been determined to have six 25S and two 5S rDNA loci (Liu and Davis 2011; Shulaev et al. 2011). Thus, we expected the pentaploids to have eight $25 \mathrm{~S}$ and two $5 \mathrm{~S}$ rDNA loci, of which five $25 \mathrm{~S}$ and one $5 \mathrm{~S}$ locus were derived from $F$. virginiana. Besides 5xAJ, we examined other pentaploid individuals and found that about a half of them did show eight $25 \mathrm{~S}$ loci while others showed nine as in $5 \mathrm{xAJ}$ (Liu et al. 2012).

By putting together the GISH and the rDNA-FISH results on $5 \mathrm{xAJ}$, we were able to assign five 25S rDNA loci to the group of 21 chromosomes with GISH signals generated by the F. iinumae DNA probe. The other four $25 \mathrm{~S}$ and the two $5 \mathrm{~S}$ loci were assigned to the chromosome group with the weakest GISH signals, which were presumed to be the $F$. vesca 'Hawaii4' and F. vesca-like genome copies. By subtracting the one $5 \mathrm{~S}$ and three $25 \mathrm{~S}$ loci expected in the F. vesca 'Hawaii4' subgenome copy, the remaining one 25S and one 5S rDNA 
loci were assigned to the octoploid-derived, F. vesca-like genome in 5xAJ. Given that all the examined diploid species showed 25S rDNA locus numbers of two or three, and a consistent 5S locus number of one in a single genome copy (Liu and Davis 2011), this result suggests that genomic loss of $25 \mathrm{~S}$ rDNA loci has occurred both in $F$. vesca-like and $F$. iinumae-like subgenome groups, while the latter group has also lost all of its 5S rDNA loci.

\section{Discussion}

An early GISH application in strawberry was aimed at verification of an interspecific hybrid from a cross between diploid $F$. nilgerrensis and the cultivated octoploid $F$. ×ananassa (Ma et al. 2005). In that pentaploid hybrid, the seven chromosomes derived from $F$. nilgerrensis were visually isolated by an F. nilgerrensis probe from the rest of the pentaploid's chromosomes. Our diploid hybrid 'YWx1358' also involved an F. nilgerrensis genome, which was differentiated from the $F$. vesca-derived genome by cGISH. In molecular phylogenetic studies (Rousseau-Gueutin et al. 2009; DiMeglio et al. 2014), F. nilgerrensis alleles were located in a clade distant from those populated by alleles from $F$. vesca and the octoploids, indicating its relatively distant phylogenetic relationships to those species. The unambiguous genomic differentiation between $F$. nilgerrensis and both $F$. vesca and $F$. ×ananassa by our cGISH work and that of Ma et al. (2005), also indicates their distant relationships. On this basis, F. nilgerrensis could be excluded from consideration as a possible diploid ancestor to the octoploids.

Compared to the distance between $F$. nilgerrensis and $F$. vesca, a lesser distance between F. viridis and $F$. vesca was suggested by two phylogenetic studies, involving the nuclear gene 
GBSSI-2 (Rousseau-Gueutin et al. 2009) and the chloroplast genome (Njuguna et al. 2013), while $F$. nilgerrensis and $F$. viridis were diverged from $F$. vesca to similar extents in studies based on the nuclear genes ADH (DiMeglio et al. 2014) and DHAR (Rousseau-Gueutin et al. 2009). These molecular divergence patterns are at least partially congruent with our results, in which we observed decreased resolution of GISH in differentiating $F$. viridis and $F$. vesca genomes in triploid $F$. $\times$ bifera, in contrast to the greater differentiation of $F$. nilgerrensis and F. vesca genomes in hybrid 'YWx1358'. Since we used Cot-1 DNA of $F$. vesca as a block, the reduced signal resolution may be partly because single- and low-copy DNA sequences were not blocked. Those few GISH signal sites in the F. vesca genome may indicate regions enriched with low-copy sequences. A better resolution might be achieved if total genomic DNA is used as a block. Nevertheless, our GISH result in $F$. $\times$ bifera may imply that it could be very difficult to separate any two strawberry genomes with a distance less than that between $F$. viridis and $F$. vesca by GISH, given that discriminating between more closely related genomes is more difficult than discriminating between more divergent genomes (Kato et al. 2005).

F. iinumae, like F. nilgerrensis, has been suggested by multiple phylogenetic studies to be highly divergent from F. vesca (Rousseau-Gueutin et al. 2009; Njuguna et al. 2013; DiMeglio et al. 2014; Tennessen et al. 2014). Therefore, GISH should be able to differentiate F. vescaand F. iinumae-like subgenomes in the octoploids, which are suggested to contain genomes from both sources (Rousseau-Gueutin et al. 2009; DiMeglio et al. 2014; Tennessen et al. 2014). On the other hand, genomes other than these two in the octoploids may not be 
discriminated independently if they are too close to each other and/or to either $F$. vesca or $F$. iinumae. The first assumption was confirmed by our GISH and cGISH results on the pentaploid hybrids. The results not only confirmed the existence of both $F$. vesca- and $F$. iinumae-like genomes in octoploid species $F$. virginiana, but also quantified a gametic $(n=4 x$ $=28$ ) subgenome copy number ratio of 1:3 between the $F$. vesca-like genome group and the $F$. iinumae-like group. This result supports Tennessen et al. (2014) and Sargent et al. (2015)'s findings that there is only one pair of $F$. vesca-like genome copies in the studied octoploid accessions, based on differing types of evidence.

Recently, Nathewet and Yanagi (2014) reported their GISH attempts on F. ×ananassa using both mitotic and meiotic chromosomes and genomic DNAs of F. iinumae, F. vesca, and F. nipponica, as probes. In their report, 35 mitotic chromosomes had signals when hybridized with F. iinumae DNA, while in separate assays 12-14 mitotic chromosomes had signals when hybridized with $F$. vesca DNA but only in telomeric regions of short arms, and "tip" regions of about five bivalents had signals with $F$. nipponica DNA. This outcome is similar to our results in many more chromosomes had affinity to $F$. iinumae DNA than to $F$. vesca DNA.

In the present study, the differing signal levels among chromosomes in the F. iinumae-like group as shown by cGISH indicate that there may be at least two types of "non- $F$. vesca-like" subgenome contributors to the origin of $F$. virginiana, but also that distinguishing among them may not be possible by GISH due to lack of sufficient divergence among them. Discovery of as yet unknown Fragaria diploid species may provide an opportunity to test this hypothesis.

Our previous work on chromosomal localization of ribosomal DNA in various polyploid 
strawberries indicated a severe reduction in locus numbers of both $25 \mathrm{~S}$ and $5 \mathrm{~S}$ rDNA in octoploids, in which 16 to $2425 \mathrm{~S}$ and eight $5 \mathrm{~S}$ loci were expected as the $4 \mathrm{x}$ multiple of the numbers found in diploids, but only ten $25 \mathrm{~S}$ and two $5 \mathrm{~S}$ loci were actually identified (Liu and Davis 2011). There we hypothesized that all 25S rDNA loci in F. iinumae-derived subgenome could have been lost. In the present study, we were able to assign rDNA loci to the differentiated $F$. vesca- and $F$. iinumae- like chromosome groups by combining rDNA-FISH and a GISH examination together, and observed that both groups had some loss but also some retention of $25 \mathrm{~S}$ rDNA loci, while only the $F$. vesca-like subgenome retained its 5S rDNA. Njuguna et al. (2013) suggested $F$. vesca subsp. bracteata as the most closely related genome to the $F$. vesca-like genome in octoploids. F. vesca subsp. bracteata was observed to have six 25S rDNA loci (Liu and Davis 2011). Also, most Asian diploid species were revealed with the same 25S rDNA locus number except for F. nilgerrensis and F. nipponica, which have four and five $25 \mathrm{~S}$ loci, respectively. However, those two species were less likely to be involved in the origination of the octoploids as suggested by phylogenetic studies. Therefore, we assume that, in the absence of evolutionary loss of rDNA loci, the hypothetical "original" octoploid genome had twenty-four $25 \mathrm{~S}$ loci and eight $5 \mathrm{~S}$ loci, on which basis the presence of lower numbers of rDNA loci is the consequence of loss (Liu and Davis 2011). On this basis, the $F$. vesca-like subgenome copies have evidently lost two-thirds of their 25S loci and retained both of their 5S loci, while the F. iinumae-like subgenome group has lost about half of its 25S loci and all of its $5 \mathrm{~S}$ loci.

Among different pentaploid individuals, 25S rDNA locus numbers of eight and nine were 
observed. As eight was the expected locus number, the additional locus could have been recovered from a previously eliminated locus. Rho et al. (2012) reported twelve 45S rDNA loci in an F. ×ananassa variety. We did not study $F$. ×ananassa but found only ten $25 \mathrm{~S}$ loci in both F. virginiana and F. chiloensis (Liu and Davis 2011). In the diploid hybrid 'YWx1358', whose parents both showed four $25 \mathrm{~S}$ loci, four $25 \mathrm{~S}$ loci were unsurprisingly observed. However, their reciprocal hybrid '1358xYW' presented six 25S loci instead (data not shown). These interesting results lead us to speculate that hybridization events may somehow (in some cases) trigger a recovery of rDNA loci and this recovery may have some bias to the direction of crossing. There was a similar finding in a trigenomic allopolyploid Cardamine x schulzii, where Zozomova-Lihova et al. (2014) revealed novel rDNA loci that were suggested to be reinstalled by translocation of genes from partner genomes.

GISH patterns displayed a contrast between $F$. $\times$ bifera and $5 \times \mathrm{AJ}$ with respect to the illumination of rDNA loci. The rDNA loci in the $F$. viridis subgenomes of $F$. $\times$ bifera were all detected as exceptionally bright, localized signals by $F$. viridis genomic DNA, while no exceptionally bright signals coinciding with detected rDNA loci were seen when F. iinumae DNA was hybridized to 5xAJ chromosomes. The detection of $F$. viridis rDNA loci in $F$. $\times$ bifera implied that those rDNA loci still retained a high homology with those of $F$. viridis. The evident lack of homogenization of rDNA loci between subgenomes in $F$. ×bifera may suggest a recent arising of this hybrid species, or at least of the accession studied. Contrastingly, the case of 5xAJ may suggest that rDNA loci derived from F. iinumae and related ancestors have undergone homogenization between the F. vesca- and F. iinumae- like 
groups of $F$. virginiana, and have diverged from the ones in extant $F$. iinumae. This could be supported by the work of Potter et al. (2000), in which no homology of ITS was found between F. iinumae and any octoploids. Tennessen et al. (2014) suggested that extensive unidirectional introgression had converted $F$. iinumae-like subgenomes to be more $F$. vescalike. Whether the homogenization of rDNA sequences was unidirectional among octoploid subgenomes is yet to be determined by future studies, which could also help us answer the question proposed previously as whether a potential "recovery" of rDNA loci had a bias to the direction of crossing. When the complete genome composition of octoploid strawberries is defined, we would have a chance to explore any potential homogenization pathways of genes between subgenomes. Findings will open new insights to polyploid evolution and guide future breeding and genetic improvements of strawberries as well.

\section{Acknowledgements}

Partial funding was provided by the New Hampshire Agricultural Experiment Station (NHAES). This is Scientific Contribution Number 2623. Support for this research has come from USDA-CSREES NRI Plant Genome Grant 2008-35300-04411, and USDA National Institute of Food and Agriculture Hatch Projects NH00433 and NH00535.

\section{References}

Ali, H.B., Lysak, M.A., and Schubert, I. 2004. Genomic in situ hybridization in plants with small genomes is feasible and elucidates the chromosomal parentage in interspecific Arabidopsis hybrids. Genome, 47(5): 954-960. doi:10.1139/g04-041.

Bringhurst, R.S. 1990. Cytogenetics and evolution in American Fragaria. HortScience, 25(8): 
879-881. Available from http://hortsci.ashspublications.org/content/25/8/879.full.pdf [accessed 8 Aug 2015].

Darrow, G.M. 1966. The strawberry: history, breeding and physiology. Holt, Rinehart and Winston, New York, N.Y.

Davis, T.M., Shields, M.E., Zhang, Q., Poulsen, E.G., Folta K.M., Bennetzen J.L., and San Miguel P. 2009. The strawberry genome is coming into view. In: J. Lopez-Medina (ed.). Proceedings of the $\mathrm{VI}^{\text {th }}$ International Strawberry Symposium. Acta Hort, 842: 533-536.

DiMeglio, L.M., Staudt, G., Yu, H., and Davis, T.M. 2014. A phylogenetic analysis of the genus Fragaria (strawberry) using intron-containing sequence from the $A D H-1$ gene [online]. PLoS ONE, 9 (7): e102237. doi:10.1371/journal.pone.0102237.

Fedorova, M.J. 1946. Crossability and phylogenetic relations in the main European species of Fragaria. Compt. Rend. Acad. Sci., 52: 545-547.

Folta, K.M., and Davis, T.M. 2006. Strawberry genes and genomics. Crit. Rev. Plant Sci., 25: 399-415. doi:10.1080/07352680600824831.

Harrison, R.E., Luby, J.J., and Furnier, G.R. 1997. Chloroplast DNA restriction fragment variation among strawberry (Fragaria spp.) taxa. J. Amer. Soc. Hort. Sci., 122(1): 63-68. Available from http://journal.ashspublications.org/content/122/1/63.full.pdf [accessed 8 Aug 2015].

Kato, A., Vega, J.M., Han, F., Lamb, J.C., and Birchler, J.A. 2005. Advances in plant chromosome identification and cytogenetic techniques. Curr. Opin. Plant Biol., 8: 148154. doi:10.1016/j.pbi.2005.01.014. 
Liu, B., and Davis, T.M. 2011. Conservation and loss of ribosomal RNA gene sites in diploid and polyploid Fragaria (Rosaceae) [online]. BMC Plant Biol., 11: 157. doi:10.1186/1471-2229-11-157.

Liu, B., Zhang, Q., Poulsen, E.G., and Davis, T.M. 2011. Molecular cytogenetics of 25S and 5S ribosomal RNA genes and dual-color GISH in strawberry (Fragaria spp.). Plant and Animal Genome XIX. San Diego, CA, January 15-19.

Liu, B., Poulsen, E.G., Zhang, Q., and Davis, T.M. 2012. Tracing the subgenomes in pentaploid hybrid strawberries. Plant and Animal Genome XX. San Diego, CA, January 14-18.

Ma, H., Chen, P., Yu, G., and Ren, L. 2005. GISH and RAPD detecting the interspecific hybrids from the cross of Fragaria nilgerrensis Schlecht. X F. xananassa Duch. Journal of Plant Genetic Resources-Beijing, 6(3): 225-261. [in Chinese].

Marx, V. 2013. The genome jigsaw: advances in high-throughput sequencing are accelerating genomics research, but crucial gaps in data remain. Nature, 501: 263-268. doi:10.1038/501261a.

Nathewet, P., and Yanagi, T. 2014. Chromosome observation methods in the genus Fragaria. Proc $7^{\text {th }}$ Intl Strawberry Symp. Acta. Hort., 1049.

Njuguna, W., Liston, A., Cronn, R., Ashman, T., and Bassil, N. 2013. Insights into phylogeny, sex function and age of Fragaria based on whole chloroplast genome sequencing. Mol. Phyl. Evol., 66(1): 17-29. doi:10.1016/j.ympev.2012.08.026.

Orcheski, B.B., and Davis, T.M. 2010. An enhanced method for sequence walking and 
paralog mining: TOPO ${ }^{\circledR}$ Vector-Ligation PCR. BMC Res. Notes, 3: 61. doi:10.1186/17560500-3-61.

Osuji, J., Harrison, G., Crouch, J., and Heslop-Harrison, J.S. 1997. Identification of the genomic constitution of Musa L. lines (bananas, plantains and hybrids) using molecular cytogenetics. Ann. Bot., 80(6): 787-793. doi:10.1006/anbo.1997.0516.

Potter, D., Luby, J.J., and Harrison, R.E. 2000. Phylogenetic relationships among species of Fragaria (Rosaceae) inferred from non-coding nuclear and chloroplast DNA sequences. Syst. Bot., 25(2): 337-348. doi:10.2307/2666646.

Poulsen, G.E. 2010. Using pentaploids as tools for studying genomic composition and allele transmission patterns in octoploid Fragaria. M.Sc. thesis, Department of Biological Sciences, University of New Hampshire, Durham, N.H.

Rho, I.R., Hwang, Y.J., Lee, H.I., Lee, C., and Lim, K.B. 2012. Karyotype analysis using FISH (fluorescence in situ hybridization) in Fragaria. Sci. Hortic., 136: 5-100. doi:10.1016/j.scienta.2011.12.025.

Rousseau-Gueutin, M., Gaston, A., Aïnouche, A., Aïnouche, M.L., Olbricht, K., Staudt, G., Richard, L., and Benoyes-Rothan, B. 2009. Tracking the evolutionary history of polyploidy in Fragaria L. (strawberry): new insights from phylgenetic analysis of lowcopy nuclear genes. Mol. Phyl. Evol., 51: 515-530. doi:10.1016/j.ympev.2008.12.024.

Sargent, D.J., Yang, Y., Surbanovski, N., Bianco, L., Buti, M., Velasco, R., Giongo, L., and Davis, T.M. 2015. HaploSNP affinities and linkage map positions illuminate subgenome composition in the octoploid, cultivated strawberry (Fragaria xananassa). In press, 
published online July 10, 2015. http://dx.doi.org/10.1016/j.plantsci.2015.07.004.

Senanayake, Y.D.A., and Bringhurst, R.S. 1967. Origin of Fragaria polyploids I. Cytological analysis. Amer. J. Bot., 54(2): 221-228. Available from http://www.jstor.org/stable/2440801 [accessed 8 Aug 2015].

Shulaev, V., Sargent, D.J., Crowhurst, R.N., et al. 2011. The genome of woodland strawberry (Fragaria vesca). Nat. Genet., 43: 109-118. doi:10.1038/ng.740.

Staudt, G., DiMeglio, L.M., Davis, T.M., and Gerstberger, P. 2003. Fragaria xbifera Duch.: Origin and taxonomy. Bot. Jahrb. Syst., 125: 53-72.

Tennessen, J.A., Govindarajulu, R., Ashman, T., and Liston, A. 2014. Evolutionary origin and dynamics of octoploid strawberry subgenomes revealed by dense targeted capture linkage maps. Genome Biol. Evol., 6(12): 3295-3313. doi:10.1093/gbe/evu261.

Zwick, M.S., Hanson, R.E., McKnight, T.D., Islam-Faridi, M.N., Stelly, D.M., Wing, R.A., and Price, H.J. 1997. A rapid procedure for the isolation of Cot-1 DNA from plants. Genome, 40(1): 138-142. doi:10.1139/g97-020.

Zozomova-Lihova, J., Mandakova, T., Kovarikova, A., Muhlhausen, A., Mummenhoff, K., Lysak, M.A., and Kovarik, A. 2014. When fathers are instant losers: homogenization of rDNA loci in recently formed Cardamine $\mathrm{x}$ schulzii trigenomic allopolyploid. New Phytol., 203(4): 1096-1108. doi:10.1111/nph.12873. 


\section{Figure Legends:}

Figure 1: Differentiation of $F$. vesca 'Yellow Wonder' (red) and F. nilgerrensis CFRA1358 (green) subgenomes by comparative GISH (cGISH) in diploid hybrid 'YWx1358'. (a) A somatic metaphase chromosome complement with preferential hybridizations to $F$. vesca (red) and F. nilgerrensis (green) probes, respectively; (b,c) Chromosomes derived from F. vesca (Fv) and F. nilgerrensis (Fn) were separated and shown with (b) and without (c) DAPI background.

Figure 2: GISH and rDNA-FISH in $F$. $\times$ bifera triploid GS104. (a) GISH with $F$. viridis probe (green) and F. vesca 'Hawaii4' Cot-1 as block showed relative stronger signals on 15 chromosomes than the other six (orange arrows); six distal regions were intensely highlighted by $F$. viridis probe (white arrows); (b) A sequential FISH with $25 \mathrm{~S}$ and $5 \mathrm{~S}$ rDNA probes revealed nine $25 \mathrm{~S}$ (red) and three $5 \mathrm{~S}$ (green) rDNA loci. The white arrowhead points to a $25 \mathrm{~S}$ rDNA locus that was not highlighted in GISH, indicating that this $25 \mathrm{~S}$ rDNA-bearing chromosome is derived from $F$. vesca but still has some hybridization to $F$. viridis probe in GISH.

Figure 3: Differentiation of $F$. vesca- and $F$. iinumae- like subgenomes by cGISH in the pentaploid individual $5 \mathrm{xH}$. (a) A somatic metaphase chromosome complement with preferential hybridizations to $F$. vesca (red) and $F$. iinumae (green) probes, respectively; $(\mathrm{b}, \mathrm{c})$ F. vesca derived (Fv), F. vesca-like ('Fv'), and F. iinumae-like ('Fi') subgenomes were 
separated based on their signal intensities and are shown with (b) and without (c) DAPI background.

Figure 4: GISH and rDNA-FISH in the pentaploid individual 5xAJ. (a) GISH with $F$. iinumae probe (green) and F. vesca DNA as block showed prevalent hybridizations on 21 chromosomes; (b) A sequential FISH with 25S and 5S rDNA probes revealed nine 25S (red) and two 5S (green) rDNA loci. Arrows showed the five 25S rDNA loci in F. iinumae-like subgenomes and arrowheads showed the four 25S rDNA loci in F. vesca derived and F. vescalike subgenomes. 

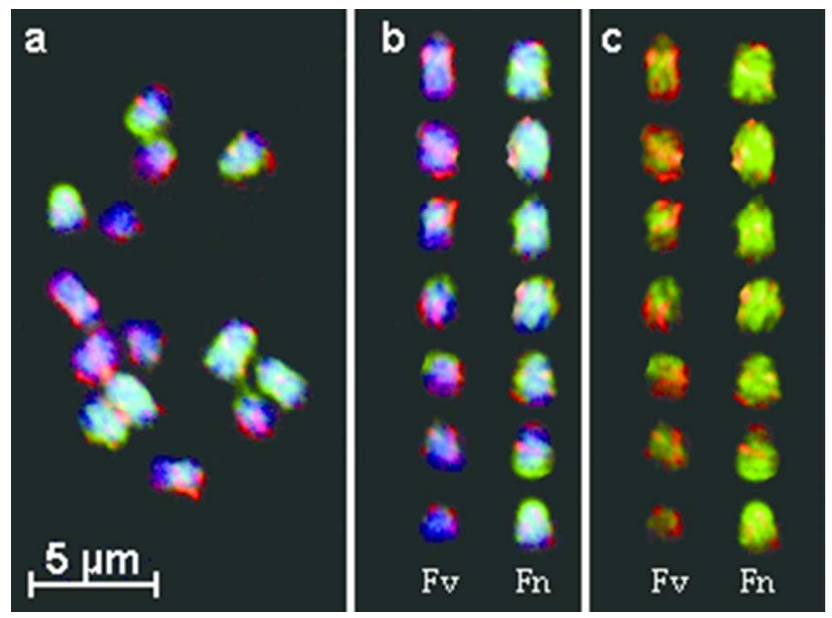

Figure 1: Differentiation of F. vesca 'Yellow Wonder' (red) and F. nilgerrensis CFRA1358 (green) subgenomes by comparative GISH (cGISH) in diploid hybrid 'YWx1358'. (a) A somatic metaphase chromosome complement with preferential hybridizations to $F$. vesca (red) and $F$. nilgerrensis (green) probes, respectively; $(b, c)$ Chromosomes derived from $F$. vesca (Fv) and $F$. nilgerrensis (Fn) were separated and shown with (b) and without (c) DAPI background. $52 \times 39 \mathrm{~mm}(150 \times 150 \mathrm{DPI})$ 

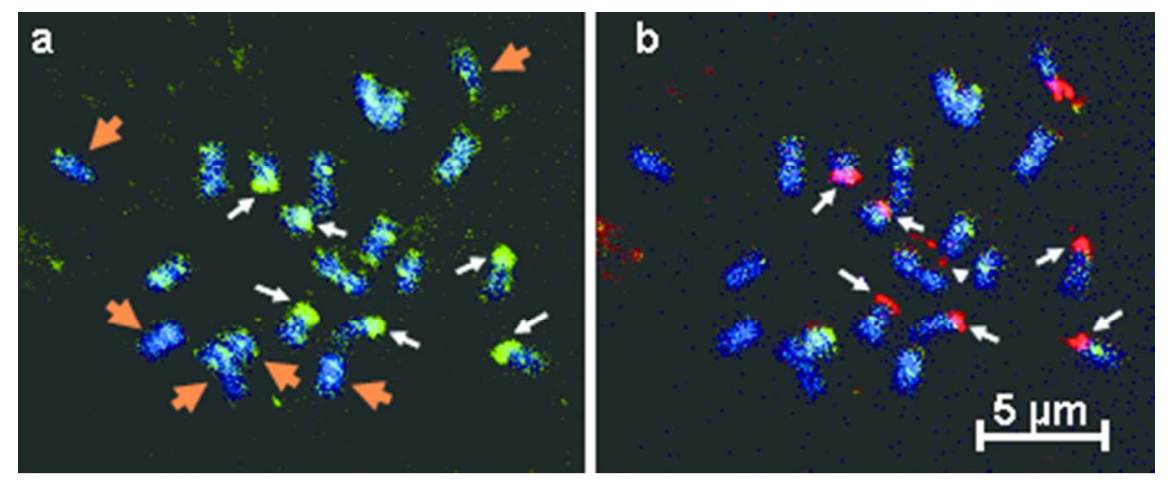

Figure 2: GISH and rDNA-FISH in $F$. x bifera triploid GS104. (a) GISH with $F$. viridis probe (green) and $F$. vesca 'Hawaii4' Cot-1 as block showed relative stronger signals on 15 chromosomes than the other six (orange arrows); six distal regions were intensely highlighted by $F$. viridis probe (white arrows); (b) A sequential FISH with $25 S$ and 5S rDNA probes revealed nine $25 S$ (red) and three 5S (green) rDNA loci. The white arrowhead points to a $25 \mathrm{~S}$ rDNA locus that was not highlighted in GISH, indicating that this $25 \mathrm{~S}$ rDNAbearing chromosome is derived from $F$. vesca but still has some hybridization to $F$. viridis probe in GISH. $73 \times 29 \mathrm{~mm}(150 \times 150 \mathrm{DPI})$ 

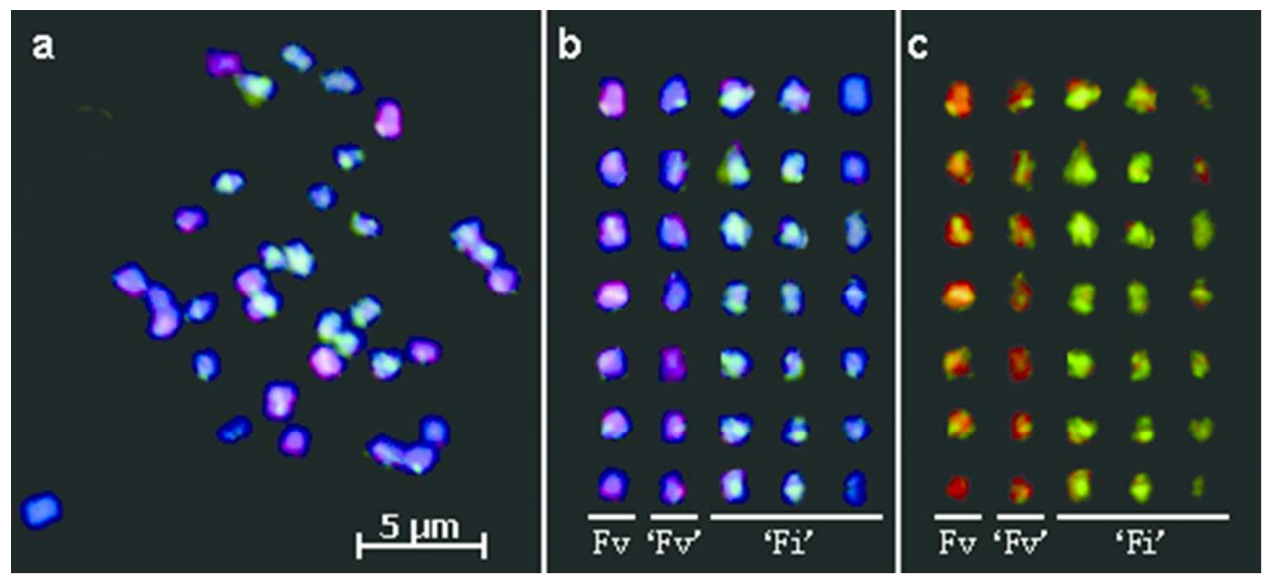

Figure 3: Differentiation of $F$. vesca- and $F$. iinumae- like subgenomes by cGISH in the pentaploid individual $5 \times \mathrm{H}$. (a) A somatic metaphase chromosome complement with preferential hybridizations to $F$. vesca (red) and $F$. iinumae (green) probes, respectively; $(b, c) F$. vesca derived $(F v), F$. vesca-like (' $F v ')$, and $F$. iinumaelike ('Fi') subgenomes were separated based on their signal intensities and are shown with (b) and without (c) DAPI background.

$81 \times 36 \mathrm{~mm}(150 \times 150 \mathrm{DPI})$ 

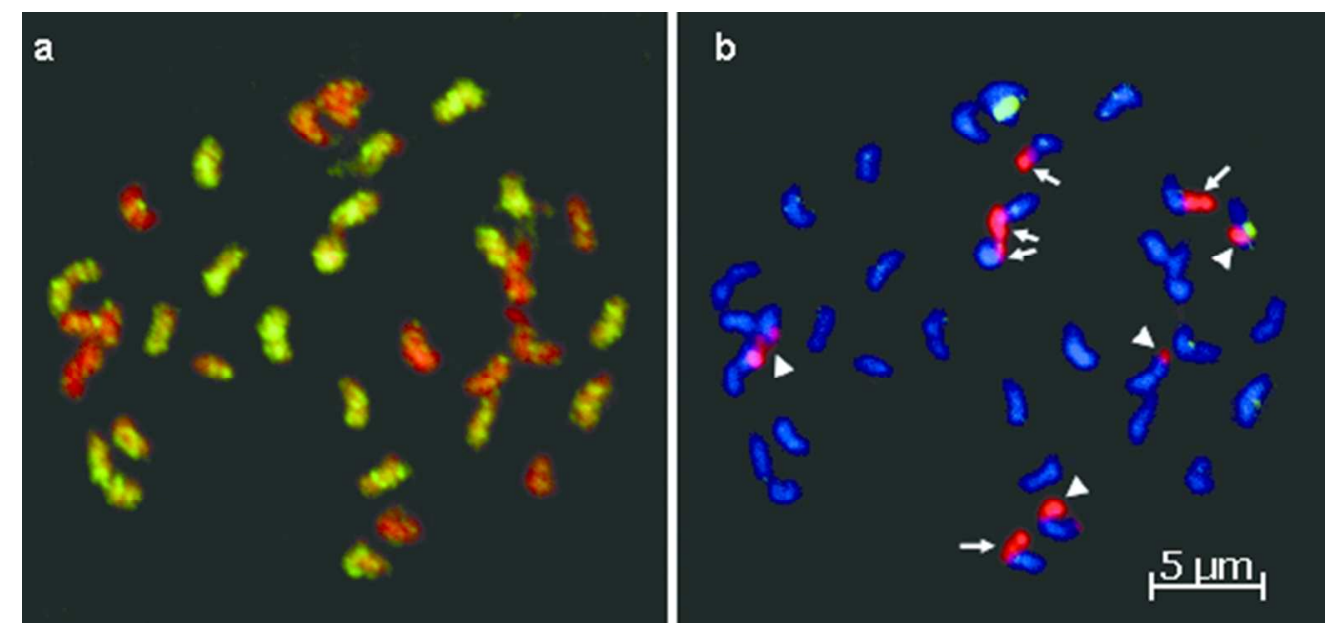

Figure 4: GISH and rDNA-FISH in the pentaploid individual 5XAJ. (a) GISH with $F$. iinumae probe (green) and $F$. vesca DNA as block showed prevalent hybridizations on 21 chromosomes; (b) A sequential FISH with $25 \mathrm{~S}$ and $5 \mathrm{~S}$ rDNA probes revealed nine 25S (red) and two 5S (green) rDNA loci. Arrows showed the five 25S rDNA loci in $F$. iinumae-like subgenomes and arrowheads showed the four 25S rDNA loci in $F$. vesca derived and $F$. vesca-like subgenomes.

$94 \times 44 \mathrm{~mm}(150 \times 150 \mathrm{DPI})$ 